\title{
Comparative study of transperineal and transvaginal sonography for localization of placenta in antepartum haermorrhage
}

\author{
Pushpa Dahiya ${ }^{1}$, Shaveta Jain ${ }^{1}$, Neelam Gupta ${ }^{1}$, Jyotsna sen $^{2}$, Nitin Jain ${ }^{2 *}$
}

\author{
${ }^{1}$ Department of Obstetrics \& Gynaecology, Pt. B.D Sharma, PGIMS, Rohtak, Haryana, India \\ ${ }^{2}$ Department of Radiology, Pt. B.D Sharma, PGIMS, Rohtak, Haryana, India
}

Received: 06 December 2015

Accepted: 12 December 2015

\section{*Correspondence:}

Dr. Nitin Jain,

E-mail: logindrnitin@gmail.com

Copyright: (C) the author(s), publisher and licensee Medip Academy. This is an open-access article distributed under the terms of the Creative Commons Attribution Non-Commercial License, which permits unrestricted non-commercial use, distribution, and reproduction in any medium, provided the original work is properly cited.

\begin{abstract}
Background: Haemorrhage is one of the leading causes of maternal mortality and morbidity in world in pregnant patients.Patients with antepartum haemorrhage confirmation of location of placenta by sonography is must for management. Transvaginal sonography(TVS) has main disadvantage of need of penetration of vagina and provoking vaginal haemorrhage It can also result in uterine contraction \& requirement of special transducer. Transperineal sonography(TPS) is more convenient and safer means of imaging the cervix and lower uterine segment overcoming the short coming of transabdominal sonography and eliminating the risk associated with Transvaginal sonography. Thus present study was undertaken with a view to evulate patients of antepartum haemorrhage by Transvaginal as well as by transperineal sonography to compare accuracy of transperineal with Transvaginal sonography.

Methods: Transvaginal probe was gently introduced for about 3-4 cm beyond the introitus. Distance between internal os and lower edge of placenta was measured. The diagnosis of placenta previa was made if placental edge was located within $5 \mathrm{~cm}$ of internal os. Transperineal sonography was performed with convex transducer. Bladder was kept empty The transducer was positioned directly on perineum in sagittal orientation over the labia minora with center of transducer typically posterior to urethra and anterior to vaginal orifice and measurement taken.

Results: TPS diagnosed placenta previa in 31 cases, 30 of which had placenta previa. TPS negated placenta previa in 19 cases, none of which had placenta previa. So false positive rate of TPS was found to $4.7 \%$, false negative $0 \%$ sensitivity $100 \%$ specificity $95.2 \%$. Positive predictive value of TPS was found to be $96.7 \%$ and negative predictive value of TVS was found to be $100 \%$.

Conclusions: So, to conclude transperineal sonography is easy to perform, well tolerated accurate diagnostic tool with high sensitivity specificity, positive and negative predictive values for localisation of placenta cases of APH. TVS can be replaced by TPS in cases of APH for localisation of placenta.
\end{abstract}

Keywords: Transperineal sonography, Transvaginal sonography, Placenta previa, Antepartum haemorrhage

\section{INTRODUCTION}

Haemorrhage is one of the leading causes of maternal mortality and morbidity in world. Good obstetric care has significantly reduced maternal mortality in developed countries, where it is about $14 / 100000$. But it is still very high in developed countries, where it is about 174/100000 live births. ${ }^{1}$ Although antepartum haemorrhage cannot be prevented but maternal and perinatal mortality associated with antepartum haemorrhage can be reduced significantly by precise localization of placenta. Greater sophistication of diagnosis and hopefully earlier warning of placenta previa are always helpful and this is where ultrasound now plays a very major role. 
In patients with antepartum haemorrhage confirmation of location of placenta is must before deciding the mode of delivery. Massive vaginal bleeding can result in maternal and foetal death if vaginal delivery is attempted in the presence of placenta previa. Although palpation of placenta by vaginal examination has been gold standard for diagnosis of placenta previa, such examination is done in operation room with all preparation for immediate cesarean section, because even the most gentle examination can cause torrential haemorrhage. Today however such a double set up examination is rarely necessary as placental localization can almost be obtained by careful sonography. ${ }^{2}$

First of all in 1966 Gottesfeld et al described a simple precise method for placental localization with no known foetal and maternal hazards associated with its use. They used transbdominal sonography for localization of placenta. But transabdominal sonography had high false positive and false negative rate. ${ }^{3}$

Transvaginal sonography has been used for better visualization of pelvic organs. This enables use of high frequency ultrasound wave generator of 5-7 MHz which in turn increases the resolution of picture. ${ }^{4,5}$ Transvaginal sonography has got several advantages over transabdominal sonography in localizing the placenta, including precise anatomic relationship can be defined without the pressure distortion of a distended bladder, high frequency and better resolution, much greater specificity and sensitivity and no hindrance by obesity or acoustic shadowing by foetal parts. ${ }^{4,5}$

Transvaginal sonography has main disadvantage of need of penetration of vagina. Basic fear of obstetrician in utilizing Transvaginal sonography for localization of placenta in case of antepartum haemorrhage is fear of provoking vaginal haemorrhage as it is an unwritten rule not to do any vaginal manipulations in patients of antepartum haemorrhage. It can also result in release of prostaglandins and initiations of uterine contraction and there is requirement of special transducer. ${ }^{6-8}$

Transperineal sonography is more convenient and safer means of imaging the cervix and lower uterine segment overcoming the short coming of transabdominal sonography and eliminating the risk associated with Transvaginal sonography. In this examination is performed with a $3.5 \mathrm{MHz}$ sector transducer positioned directly on perineum over the labia majora. The internal cervical os and lower edge of placenta can be well visualized. $^{7}$

The examination can be readily performed with the same transducer commonly used to image the foetus transabdominally and can rapidly visualize the internal cervical os in cases when that is not possible transabdominally. ${ }^{9}$
Because of potential disastrous consequences of missing a diagnosis of placenta previa, it is important not to underdiagnose. This condition on the other hand has large number of false positive diagnosis may result in unnecessary hospitalization and cesarean section. Route of sonoraphic localization of placenta (abdominal, vaginal, perineal) should be of maximum sensitivity with minimum false positive rate. ${ }^{9}$

Thus present study was undertaken with a view to evulate patients of antepartum haemorrhage by transvaginal as well as by transperineal sonography to compare accuracy of transperineal with transvaginal sonography.

\section{METHODS}

Present study was conducted on 50 patients admitted in labour room, Department of Obstetrics and Gynaecology, Pt. B.D Sharma PGIMS, Rohtak, Haryana, India over a period of one year

Patients of Antepartum haaemorrhage who were haemodynamically stable were included in study. Patients requiring immediate cesarean section in view of profuse bleeding were excluded from the study.

A detailed history, regarding onset and character of bleeding, any predisposing factor or associated condition like hypertension, jaundice, abdominal trauma, bleeding diathesis, parity, previous history of casarean section and curettage was taken. A general physical examination was carried out to note the vitals, any signs of pregnancy induced hypertension, to note the degree of blood loss and also to rule out any systemic disease.

An abdominal examination was done to specically look for height of uterus in relation to period of gestation, presence of malpresentation, any tenderness or rigidity of uterus, auscultation of foetal heart sounds. Necessary investigations were done in patients. Transvaginal sonography was performed using high resolution Transvaginal probe on real time ultrasound scanner $(5 \mathrm{MHz}$ and $6.5 \mathrm{MHz})$. The patient was placed in dorsal position after emptying the bladder. The vaginal probe covered with sterile condom was gently introduced for about 3-4 $\mathrm{cm}$ beyond the introitus in order to visualize the internal os and lower placental edge without coming in actual contact with cervix. Distance between internal os and lower edge of placenta was measured. The diagnosis of placenta previa was made if placental edge was located within $5 \mathrm{~cm}$ of internal os.

Transperineal sonography was performed on real time $3.5 \mathrm{MHz}$ scanner with convex transducer i.e. with same transducer with which we perform transabdominal sonography. Bladder was kept empty. A sterile condom was slipped on transducer after applying ultrasound gel on head of transducer. The transducer was positioned directly on perineum in sagittal orientation over the labia minora with center of transducer typically posterior to 
urethra and anterior to vaginal orifice. Transducer location and angle will be adjusted under sonographic central to optimize visualization.

Cases with Type I and Type II anterior placenta previa were allowed to deliver vaginally unless contraindicated and at the time of deliver placenta was examined for retroplacental clot and site of rupture of membranes for confirming localization of placenta. The distance from the site of rupture of membranes, in relation to edge of placenta was determined. If the edge of placenta was within $5 \mathrm{~cm}$ of ruptured membranes. The case was considered as placenta previa.

In case of cesarean delivery, the relation of placenta with internal os was determined.

Finding at delivery were used as standard to calculate sensitivity, specificity, negative and positive predictive values of transperineal and transvaginal sonography.

\section{RESULTS}

Table 1: Comparison of results of transvaginal and transperineal sonography.

\begin{tabular}{|lll|}
\hline & $\begin{array}{l}\text { No. of patients } \\
\text { diagnosed by } \\
\text { TVS }\end{array}$ & $\begin{array}{l}\text { No. of patients } \\
\text { diagnosed by } \\
\text { TPS }\end{array}$ \\
\hline $\begin{array}{l}\text { Placenta } \\
\text { previa }\end{array}$ & 31 & 31 \\
\hline Not previa & 19 & 19 \\
\hline Total & 50 & 50 \\
\hline
\end{tabular}

Transperineal and transvaginal sonography were carried out on 50 patients of Antepartum haemorrhage. Transperineal sonography diagnosed placenta previa in 31 patients and no previa in 19 patients of Antepartum haemorrhage. Similar results were obtained with Transvaginal sonography (Table 1).

Table 2: Comparison of result of transvaginal and transperineal sonography and delivery diagnosis.

\begin{tabular}{|lll|}
\hline No. of & $\begin{array}{l}\text { Diagnosed at } \\
\text { patients }\end{array}$ & \\
\hline $\begin{array}{l}\text { Diagnosis by TPS } \\
\text { Placenta previa }\end{array}$ & 31 & 30 \\
No previa & 19 & 20 \\
\hline Diagnosis by TVS & & \\
Placenta previa & 31 & 30 \\
No previa & 19 & 20 \\
\hline
\end{tabular}

Transperineal sonography diagnosed placenta previa in 31 cases of Antepartum haemorrhage. Out of which one was not having placenta previa which was diagnosed by placental examination at delivery. Transperineal sonography ruled out placenta previa in 19 cases none of which had placenta previa at delivery or caesarean section. Similar results were obtained with Transvaginal sonography.

As shown in Table 3, both transperineal and transvaginal sonography diagnosed Type I placenta previa in 6 cases, all of which were confirmed at delivery by placental examination.

Type II placenta previa was diagnosed in 7 patients by both transperineal and transvaginal sonography but at delivery in one patient it was found to be in upper uterine segment(UUS), in 2 patients it was Type I placenta previa while Type II placenta previa was found in 4 patients.

Major degree of placenta previa (Type III \& IV) were diagnosed in 17 cases by both transperineal and Transvaginal sonography which were later on confirmed at time of delivery.

Table 3: Comparison of results of transvaginal and transperineal sonography with delivery diagnosis for diagnosis of types of placenta previa.

\begin{tabular}{|llll|}
\hline $\begin{array}{l}\text { Type of placenta } \\
\text { previa }\end{array}$ & TVS & TPS & $\begin{array}{l}\text { Delivery } \\
\text { diagnosis }\end{array}$ \\
\hline Type I & 6 & 6 & 6 \\
\hline Type II & 7 & 7 & $\begin{array}{l}\text { UUS- } 1 \\
\text { Type I -2 } \\
\text { Type II -4 }\end{array}$ \\
\hline Type III & 1 & 1 & 1 \\
\hline Type IV & 16 & 16 & 16 \\
\hline
\end{tabular}

Table 4: Comparison of results of Transvaginal and transperineal sonography in diagnosing distance from os for type $I$.

\begin{tabular}{|llll|}
\hline $\begin{array}{l}\text { Distance from internal } \\
\text { cervical os (in cm) }\end{array}$ & TVS & TPS & $\begin{array}{l}\text { Delivery } \\
\text { diagnosis }\end{array}$ \\
\hline $4.1-5$ & 1 & 1 & 1 \\
\hline $3.1-4$ & 2 & 2 & 2 \\
\hline $2.1-3$ & 1 & 1 & 1 \\
\hline $1.1-2$ & 2 & 2 & 2 \\
\hline
\end{tabular}

Table 5: Comparison of results of transvaginal and transperineal sonography in localization of placenta in cases of Antepartum haemorrhage.

\begin{tabular}{|lll|}
\hline & TPS & TVS \\
\hline Sensitivity & $100 \%$ & $100 \%$ \\
\hline Specificity & $95.2 \%$ & $95.2 \%$ \\
\hline Positive predictive value & $96.7 \%$ & $96.7 \%$ \\
\hline $\begin{array}{l}\text { Negative predictive } \\
\text { value }\end{array}$ & $100 \%$ & $100 \%$ \\
\hline False positive rate & $4.7 \%$ & $4.7 \%$ \\
\hline False negative rate & $0 \%$ & $0 \%$ \\
\hline
\end{tabular}


Both transperineal and Transvaginal showed similar accuracy in diagnosing distance form os for Type I placenta previa.

In the present study of 50 patients of Antepartum haemorrhage sensitivity, specificity, positive and negative predictive value of transperineal and Transvaginal sonography in localization of placenta were found to be same.

\section{DISCUSSION}

Placenta previa is a term with clinical implications that is maternal risk from haemorrhage, foetal risk from prematurity, need for high caesarean section rate, possibility of placenta accreta especially if the patient has had a previous cesarean section and placenta overlies the uterine scar. $^{10}$

The present study was carried out on 50 patients admitted in labour room, Deptt. of Obstetrics and Gynaecology at Pt. B.D Sharma PGIMS, Rohtak, Haryana, India over a period of one year to compare the diagnostic accuracy of transperineal and Transvaginal sonography for localization of placenta in cases of Antepartum haemorrhage.

Transabdominal sonography was introduced by Gottesfeld et al in 1966 for diagnosing placenta previa. ${ }^{11}$ Transabdominal sonographic diagnosis of placenta previa has several inherent problems, which results in false positives diagnosis of placenta previa leading to unnecessary hospitalization and sometimes caesarean section also results. ${ }^{4,5,9}$

Being aware of false positive diagnosis, women with suspected placenta previa are often exposed to vaginal examination under anaesthesia to ruie out placenta previa. this examination may expose the patient to risk of major haemorrhage. ${ }^{4,5,9}$

So there was a need of better diagnostic technique for localization of placenta in cases of APH. Although MRI has been found to be superior than transabdominal sonography but its not cost effective and availability only at higher centress. ${ }^{10}$ In recent years Transvaginal sonography has been developed to produce high resolution picture of pelvic organs. In 1988 Farine et al studied the role of vaginal ultrasound for diagnosis of placenta previa. They reported false positives rate of $15 \%$ false negatives rate of $0 \%$ sensitivity of $100 \%$ and specificity of $88 \%$. Positives predictive value $54.5 \%$ and negative predictive value of $100 .^{11}$

In 1989 Lim et al studied the role of TVS for placental localization and reported $100 \%$ sensitivity, specificity, positive predictive value and negative predictive value. ${ }^{12}$
Farine et al in 1990 published sensitivity 100\%, specificity $81 \%$, positive predictive value of $71 \%$ and positive predictive value of $100 \%$ by Transvaginal sonography for placental localization in cases of APH. ${ }^{13}$ Leevntveld et al and Tan et al in 1990 and 1995 respectively also reported high sensitivity, sepecificity, positive predictive value and negative predictive value in localization of placenta by TVS as compared to TAS., ${ }^{44}$

In the present study false positive rate of TVS was found to be $4.7 \%$, false negative rate $0 \%$ sensitivity $100 \%$, specificity $95.2 \%$, positive predictive value, $96.7 \%$ negative predictive value $100 \%$.

Although various studies using endovaginal sonography have been promising but endovaginal probe has to be inserted cautiously while directly visualizing the cervix on screen and further adjustments in the position of probe must be made with caution to minimize the possibility of inducing bleeding in patient with possible placenta previa. $^{8}$

Endovaginal sonography is not preferred by some patients and some time it may cause torrential haemorrhage. In 1992 Hertzberg et al reported the use of transperineal sonography for localization of placenta in case of APH, which seems to be convenient and safe route of imaging the cervix, lower uterine segment, its relation with placenta and as vaginal penetration is not needed virtually eliminating the potential for inducing bleeding which is associated with endovaginal sonography. Hertzberg et al in her series reported sensitivity of $100 \%$ specificity of $90 \%$ positive predictive value of $90 \%$ negative predictive value of $100 \%$, false negative rate of $0 \%$ and false positive rate of $0.6 \%$ by transperineal sonography in cases of $\mathrm{APH} .^{8}$

In 1999 Bukshee et al studied the role of transperineal sonography in localization of placenta. They published sensitivity, specificity, negative and positive predictive value of $100 \% .^{15}$

In the present study sensitivity of transperineal sonography was found to be $100 \%$ specificity of $95.2 \%$, Positive predictive value of $96.7 \%$ negative predictive value of $100 \%$ false positive rate of $4.7 \%$ and false negative rate of $0 \%$.

So TPS and TVS have almost similar comparative accuracy reported by various authors. The present study too has shown similar results. As TPS avoids the need of penetration of probe in vagina. So it can replace TVS in localization of placenta in cases of Antepartum haemorrhage.Gouhar et al have also concluded that TPS is a valuable approach for evaluating patients with high risk of Placenta previa \& it is a safe, rapid, \& accurate technique with little patient discomfort. ${ }^{16}$ 
Sensitivity, specificity, positive predictive value, negative predictive value of TVS in location of placenta according to present study are $100 \%, 95.2 \%, 96.7 \%$ and $100 \%$ respectively which are comparable to studies done by Leerentveld, ${ }^{4}$ Farine et $\mathrm{al}^{11}$, Lim et al, ${ }^{12}$ \&Tan et al. ${ }^{14}$

Sensitivity, specificity, positive predictive value, negative predictive value of TPS in location of placenta according to present study are $100 \%, 95.2 \%, 96.7 \%$ and $100 \%$ respectively which are comparable to study of Hertzberg et al, ${ }^{8}$ Bukshee, et al. ${ }^{15}$

\section{CONCLUSION}

Both TPS and TVS are found to have similarly diagnostic, accuracy in diagnosing placenta previa..For TVS we require a special transducer but TPS can be performed readily with the same transducer that used for TAS. There is always fear in mind of obstetrician of provoking haemorrhage with use of TVS is cases of placenta previa. Patients also experience some inconvenience when vaginal probe is introduced in vagina. So, to conclude transperineal sonography easy to perform, well tolerated accurate diagnostic tool with high sensitivity specificity, positive and negative predictive values for localisation of placenta cases of APH. TVS can be replaced by TPS in cases of APH for localisation of placenta.

Funding: No funding sources

Conflict of interest: None declared

Ethical approval: The study was approved by the Institutional Ethics Committee

\section{REFERENCES}

1. The world bank. Maternal mortality ratio. Available at

http://data.worldbank.org/indicator/SH.STA.MMRT. Accessed 15 November 2015.

2. Cunningham FG, MacDonald PC, Gant NF, Leveno KJ, Levino KJ, Gilstrap LC III, et al. Williams Obstetrics, 20th ed. Stamford Connecticut: Appleton and Lange; 1997.

3. Gottesfeld KR, Thompson HE, Holmes JH, Taylor ES. Ultrasound placentography - a new method for placental localisation. Am J Obstet Gynecol. 1966; 96:538-47.

4. Leerentveld RA, Gilberts E, Arnold M, Wladimiroff JW, Accuracy and safety of Transvaginal sonographic placental localisation. Obstet Gynaecol. 1990; 76:759-62.

5. Farine D, Fox HE, Jakobson S, Timor-Tritsch IE. Is it really a placenta previa? Eur J Obstet Gynecol Reprod Biol. 1989;31:103-8.

6. Mahony BS, Nyberg DA, Luthy BA. Translabial ultrasound of third trimester uterine cervix: correlation with digital examination. J Ultrasound Med. 1990;9(12):717-23.

7. Hertzberg BS, Bowie JD, Caroll BA, Kliewer MA, Weber TM. Diagnosis of placenta previa during the third trimester: Role of transperineal sonography. Am J Radiol. 1992;159:83-9.

8. Harris RD, Barth RA. Sonography of the gravid uterus and placenta: current concepts: Am J Radio. 1993;160:455-65.

9. Townsend RR. Ultrasound evaluation of the placenta and umbilical cord. In: Callen editor. Ultrasound in Obstetrics and Gynaecology, 3rd ed. Philadelphia: WB Saunders; 1994:447-453.

10. Miller AG, Langlois SP. Placenta previa -A review with emphasis on the role of ultrasound. Aust NZJ Obstet Gynaecol. 1989;29:110-6.

11. Farine D, Fox HE, Jakobson S, Tristsch IE. Vaginal ultrasound for diagnosis of placenta previa. Am J Obstet Gynecol. 1988;159:566-9.

12. Lim BH, Tan CE Smith APM, Smith NC. Transvaginal sonography for diagnosis of placenta previa. Lancet. 1989;2:444.

13. Farine D, Peisner DB, Timor-Tristch IE. Placenta previa. Is the traditional diagnostic approach satisfactory. J Clin Ultrasound. 1990;18:328-30.

14. Tan NH, Abu M, Woo JLS, Tahir HM. The role of Transvaginal sonography in diagnosis of placenta previa. Aust N Z Obstet Gynaecol. 1995;35(I):42-5.

15. Bukshee K, Deka D Kaur P, Dadhwal V. A critical evaluation of transperineal sonography in the diagnosis of placenta previa. J Obstet Gynecol. 1999;49:51-2.

16. Gouhar G, Sadek S, Siam S, Ahmad R. Role of transperineal sonography in diagnosis of placenta previa/accreta: A prospective study. The Egyptian Journal of Radiology and Nuclear Medicine. 2012;43(4):637-45.

Cite this article as: Dahiya P, Jain S, Gupta N, Sen J, Jain N. Comparative study of transperineal and transvaginal sonography for localization of placenta in antepartum haermorrhage. Int J Reprod Contracept Obstet Gynecol 2016;5:48-52. 